\title{
Andanzas españolas de la poesía costarricense ${ }^{1}$
}

\section{Carlos Francisco Monge ${ }^{2}$}

\author{
Universidad Nacional, Costa Rica
}

\section{RESUMEN}

Se describe analíticamente un recorrido histórico de los vínculos literarios, culturales y editoriales entre la producción poética costarricense del siglo $\mathrm{xx}$, y la tradición lírica castellana. Sitúa las letras costarricenses en su contexto hispanoamericano, y señala algunos hitos que podrían explicar etapas y aspectos significativos de su desarrollo literario.

\section{Abstract}

An analytical description is provided of the literary, cultural and publishing ties existing between Costa Rican twentieth-century poetry and the Spanish lyric tradition. It situates Costa Rican letters in their Latin American context and suggests certain milestones which could explain significant stages and aspects of its literary development.

Palabras clave: Poesía costarricense, poesía española, historia literaria Keywords: Costa Rican poetry, Spanish poetry, history of literature

Una de las maneras de conocer una literatura nacional es hurgar en sus orígenes, explorar sus fuentes, cotejar sus límites; en una frase: situarla en sus entornos. Como una muestra de gratitud por recibirme,

1 Discurso de ingreso a la Academia Costarricense de la Lengua, leído el 24 de febrero de 2006.

2 Correo electrónico: cfmonge@hotmail.com. 
me valgo de esta ocasión para hablarles de las relaciones y afinidades que, en mi opinión, ha habido entre la literatura costarricense y la española. Como resulta un tema muy amplio, me limitaré a un género y a una época: la poesía del siglo xx. Por su etimología, relación es una palabra que supone al menos dos participantes: personas, entidades, países e incluso objetos. Hay relaciones diplomáticas, relaciones comerciales, relaciones públicas, relaciones de amistad, relaciones sexuales... En nuestro idioma, al entablar relaciones asumimos que entre las partes ha de haber algún tipo de vínculo, complementariedad o consecuencia; cualquier asunto puede darse menos la exclusión, el desconocimiento o el azar; así, resultaría algo extraño hablar de relaciones de enemistad, relaciones de oposición o relaciones de odio.

¿En qué consisten las relaciones literarias, entonces? Comienzo por un recuerdo personal: mi primer encuentro con la poesía española lo tuve en mi adolescencia, gracias a un tomito de la vieja colección Austral. Lo hallé en la modesta biblioteca familiar que mi padre fue reuniendo desde mis lejanos días de infancia. Era una antología de poemas de Quevedo, y muchas veces leí y releí aquellos versos que hablaban de la brevedad de la vida, de la fugacidad del tiempo y de otros asuntos que entonces apenas comprendía, aunque inexplicablemente me conmovían y cambiaban el ritmo de mi respiración. Aquellos sonetos de Quevedo - ahora lo veo así-me abrieron las puertas a un universo que siempre será difícil abarcar en su totalidad.

\section{$* * *$}

Por su historia, nosotros los hispanoamericanos hemos tenido que ver la literatura española como un referente esencial desde el que se han configurado variadísimas formas de dependencia, de filiaciones, de influencias y de rechazos. Ha desempeñado un papel ejemplar; es decir, modélico, del que se ha dependido, al que se ha imitado, sobre el que se ha desconfiado, al que se ha pasado por alto y que ha permanecido como una sombra que se alarga con el paso del tiempo, de las modas y de los modismos. Pero si queremos hablar de la poesía 
española, también tendríamos que preguntarnos: ¿cuál poesía española?; ¿de qué idiomas, períodos o regiones: la castellana, la andaluza, la gallega, la catalana; la escrita en eusquera, la de origen popular, la cultivada en los salones literarios, la que se oye en conciertos de rock, la que recita una niña en un colegio católico? Y si pensamos en épocas: ¿la medieval, la barroca, la posromántica?; ¿cuántas direcciones tomó a lo largo del siglo xx y cuánto sabemos de ellas?

La poesía española le ha hablado durante diez siglos a una historia compleja y muy rica. Se halla articulada en una tradición de larguísimo alcance y en una cultura milenaria. Un poeta español de hoy es al mismo tiempo un individuo y la encarnación de un linaje literario que empezó probablemente en el siglo XI con las jarchas mozárabes; cuando Jorge Guillén le dio a su obra como nombre general Cántico, les rendía homenaje, tal vez mundano, a los poemas de San Juan de la Cruz; y si Pedro Salinas escribió unos versos amorosos para su libro Razón de amor, lo hizo porque pensaba también en un enigmático poema del siglo XIII, con el mismo título. Esa tradición no ha sido un peso sino un yugo de oro que ha dotado a la poesía española de una doble condición: por un lado, la ha convertido en el centro solar de una tradición literaria, alrededor del cual han girado otras literaturas, incluida la costarricense; y por otro, ante tan larga trayectoria, la mejor poesía española contemporánea se ha visto compelida a dar con nuevas formas y lenguajes para afrontar las correntadas de su propia historia.

Es evidente que la principal diferencia entre la poesía española y la costarricense está en los materiales genéticos que las componen. La poesía costarricense cuenta con poco más de un siglo de desarrollo; además, sus referentes históricos son escasos en el tiempo y en su intensidad. Vivimos en un país relativamente joven, que en cierta medida se ha hecho de la historia de otros: la de España, la de Francia, la de México o la de los Estados Unidos. Con una breve evolución literaria y un pasado sin grandes hitos, la poesía costarricense se sitúa en la periferia, tanto por su condición ancilar como por haber tenido que explorar en sus alrededores. Prueba de ello es que varias obras 
poéticas que se han proyectado desde nuestro territorio han sido el resultado también, aunque no exclusivamente, de viajes, de aventuras y de descubrimientos. Hoy día leemos y reconocemos a algunos de nuestros antepasados literarios, aunque no lo suficiente; sabemos que bebieron en las fuentes europeas e hispanoamericanas, y que buena parte de sus esperanzas habían quedado cifradas no tanto en el triunfo y el éxito, sino en que se les tuviese —o se les recordase- tan solo como poetas.

Naturalmente, las circunstancias se modificaron a lo largo del siglo $\mathrm{xx}$; conforme las letras nacionales tuvieron acceso a la modernidad, le tomaron el ritmo a la historia y a los grandes movimientos y tendencias de la poesía contemporánea. Por ello, si emprendiésemos una crónica de la poesía costarricense sería necesario considerar tanto esa condición histórica ancilar como las limitadas arcas de su herencia literaria. Salvo escasos y fugaces momentos, en la poesía costarricense no hay una crítica al lenguaje, a una estética o a una tradición poética; hay tentativas por impugnar modelos de cultura, hitos históricos, arquetipos morales; en fin, modos de entender la realidad y el presente. Existen tendencias y estilos, pero el ejercicio de la poesía no se ha concebido, a mi modo de ver, como una actividad estética sino como una convicción ética, lo que explica la acogida entre muchos lectores costarricenses de la poesía de Jorge Debravo. Carecemos todavía de reflexiones sobre la poesía, porque hemos preferido detenernos no en el cómo sino en el qué de los poemas.

No deja de ser llamativo que el primer poeta costarricense de quien hay noticia fue un castellano, de origen incierto, que se trasplantó a Costa Rica a fines del siglo xvi: Domingo Jiménez, autor de unas escasas coplas. Fue un poeta menor y sin importancia literaria, excepto por el hecho de que con su ejemplo mostró que el territorio de la poesía no es un lugar geográfico, sino una lengua ${ }^{3}$. La casi desconocida

$3 \quad$ Pocas semanas después de haber leído estas páginas. el profesor y crítico literario Fernando Herrera Villalobos me envía alguna información de notable interés. que yo desconocía: poco después de 1833 aparecen en los primeros periódicos costarricenses poemas de Núñez de Arce, de 
existencia de Domingo Jiménez es, al mismo tiempo, una metáfora de los orígenes de la poesía costarricense y tal vez la de toda la hispanoamericana. Desde el punto de vista historiográfico, no tenemos claro cuándo nació la poesía costarricense, aunque haya algunos documentos que revelan su existencia desde la época colonial; peroel desarrollo de su historia empieza en la última década del siglo XIX, con ciertas obras de resabios románticos y premodernistas. En la Lira costarricense (1890) se reúne la más conocida muestra de la poesía culta que se escribía entonces ${ }^{4}$, en la que predomina un discurso poético más bien convencional, circunscrito a los motivos, estilos y tendencias de la época. Fue un primer impulso de las musas en tierras costarricenses. Si bien sus autores tenían algún conocimiento de la tradición culta de la poesía española, no contaban con una cultura literaria muy profun$\mathrm{da}$, tal vez porque apenas estaban construyendo su patria y no pensaban sino en el destino de sus circunstancias y de las propias urgencias del día.

Después de la Lira costarricense, hubo un segundo impulso llevado adelante por unos jóvenes poetas vinculados al periodismo o a la actividad política, que tuvieron la oportunidad de conocer la literatura de su época; eran Justo A. Facio, Aquileo J. Echeverría (el modernista), Lisímaco Chavarría, Rafael Cardona, Rafael Ángel Troyo, Carlos Gagini y Francisco Soler. Buscaron trasplantar en el decir un espíritu moderno, aunque no correspondiera del todo con una idea del mundo y mucho menos con su propio entorno. En sus pequeños libros y poemas dispersos confluyen la poesía tradicional decimonónica y ecos del arte nuevo de entonces. Hay en ellos una mezcla más o menos asonantada de los tonos literarios de Núñez de Arce, Bécquer, Villaespesa, tal vez Salvador Rueda, Enrique de Mesa

Campoamor, de Zorrilla; y que el primer libro de poemas editado en Costa Rica data de 1833, del español Gaspar Fernández de Ávila. Años después, otros dos poetas españoles publicaron su obra en estos lares: José A. Mendoza, desde 1845, y Juan Fernández Ferraz, quien desde 1871 publicó poemas. Agradezco al colega Herrera Villalobos estos nuevos datos.

4 Máximo Femández, comp. Lira costarricense (San José: Tipografía Nacional, 1890-1891). Dos tomos. 
o Ángel Ganivet, junto a los vibrantes coros de nuestro entorno: Darío, Valencia, Herrera y Reissig, Lugones.

Treinta años después de la aparición de la Lira costarricense, nuestra poesía se logró situar en el mapa editorial español, cuando en 1921 se publicó en Barcelona el Parnaso costarricense, antología hecha por el venezolano Rafael Bolívar Coronado, y en 1928 apareció en Madrid la antología Los mejores poetas de Costa Rica, reunida por el gaditano Eduardo de Ory, con prólogo de Alejandro Alvarado Quirós. Ambas recopilaciones fortalecieron los contactos entre las letras españolas modernas y las costarricenses. Las librerías josefinas también hicieron lo suyo porque, gracias a su diligencia, algunos libreros, periodistas, maestros y editores, como Joaquín García Monge, supieron estimular la importación de buenas obras, clásicas y modernas. Debió de ser una época en que una docena de amigos hurgaban en las librerías o entre los anaqueles de las pequeñas bibliotecas familiares; se intercambiaban afanosamente libros, leían y comentaban en los parques josefinos los títulos recién llegados. A partir de entonces menudearon las relaciones más directas entre costarricenses y españoles, en parte por el papel mismo de algunas revistas literarias y en parte por las amistades personales con varios intelectuales españoles.

Desde luego, los vínculos con España y su literatura han sido variados y de muy diversa índole. Nuestro viejo poeta Aquileo J. Echeverría pasó los últimos meses de su vida en Barcelona. Allí no tuvo tiempo siquiera de hacer «vida literaria»; murió en 1909 a sus 43 años, sin llegar a ver impresa la segunda edición de sus Concherías, que con prólogo de Rubén Darío aparecería poco después en aquella ciudad $^{5}$. Aquileo fue buen lector de clásicos españoles y de los poetas de su tiempo; ello le mostró un buen panorama del desarrollo de la poesía moderna, aunque por una curiosa paradoja su nada moderno tomo de Concherías fue la primera incursión de la poesía costarricense

$5 \quad$ Aquileo J. Echeverría. Concherí as. Prólogo de Rubén Darío (Barcelona: Imprenta Elzeviriana de Borrás y Mestres. 1909). 
al ambiente editorial español. Hay otros ejemplos de escritores costarricenses modernistas en España: Carlos Gagini había estado en la península ibérica durante un breve período; de Rogelio Sotela apareció una segunda edición de su Recogimiento, en Madrid en 1925, y de Roberto Brenes Mesén su libro En busca del Grial, una década después. Un escritor con más fortuna fue Max Jiménez quien pasó varios años en Europa, donde imprimió en talleres madrileños dos libros: Sonaja (1930) y Quijongo (1933). Jiménez fue quien más nos acercó a los movimientos artísticos de vanguardia; trabó amistad con célebres de la época como Benjamín Jarnés, Mauricio Bacarisse, Ramón J. Sender o Enrique Díez-Canedo, y qué duda cabe de que su obra pictórica y sus esculturas quedaron bien engarzadas en las aventuras vanguardistas de esos días. El novelista José Marín Cañas, primero, y el poeta Fernando Centeno Güell, años después, vivieron también alguna temporada en España; el primero, de ascendencia española, fue a prepararse en ingeniería civil; Centeno Güell a especializarse en estudios pedagógicos. Ambos aprovecharon su estancia en tierras castellanas; conocieron los vaivenes y fragores de los movimientos vanguardistas, al punto de que Marín Cañas produjo una de las pocas novelas que agitaron los hábitos narrativos y linguiísticos costarricenses: Tú la imposible (1931). Centeno Güell abandonó para siempre el oneroso modernismo de sus poemas juveniles y se adentró, con cierta influencia del surrealismo, por los meandros del esteticismo y de una forma particular de la llamada poesía pura.

Una generación de poetas especialmente cautivada por la tradición hispánica fue la del grupo que publicó sus primeros libros en el decenio de 1950. Mencionaré a tres de ellos: Ricardo Ulloa Barrenechea, Jorge Charpentier y Carlos Rafael Duverrán. La influencia de la poesía española moderna, sobre todo de la generación del 27, es visible en su propia generación. Ulloa Barrenechea vivió varios años en Madrid, que los empleó en conocer a algunas personalidades del mundo de las letras y de la pintura; de ellas destaco su personal amistad con Vicente Aleixandre, quien se convirtió en su maestro y casi en su 
mentor. Estando en Madrid, Ulloa Barrenechea publicó dos pequeños libros: Cantares y poemas de soledad (1957) y Poesía y cristal (1958). Seguramente, cuando el poeta costarricense reunió los poemas de su libro Corazón de una historia, publicado en San José en 1962, le rendía también homenaje a Historia del corazón, de Aleixandre. Jorge Charpentier hizo sus estudios universitarios superiores en Madrid; sus primeros libros de poemas aparecieron en pequeñas ediciones de imprentas madrileñas, entre 1955 y 1959. Nunca perdió contacto con la poesía peninsular contemporánea, como lo muestran sus lecturas y sus viajes posteriores a España; ya en Costa Rica, como profesor universitario dedicó muchos años a sus buenas lecciones sobre literatura española. Carlos Rafael Duverrán estuvo en Málaga en 1973 durante una breve temporada, para asistir a unos cursos dirigidos a profesores de Español. Fue su oportunidad para actualizar su carrera y para refrescarse un poco en la poesía española de aquellos años; por un lado, escuchando las voces de quienes ya eran clásicos contemporáneos: Aleixandre, Carlos Bousoño, Dámaso Alonso, Claudio Rodríguez; por otro, conociendo las voces jóvenes que empezaban a hacerse oír, como las de Francisco Brines, José Ángel Valente o Félix Grande. En Málaga publicó el opúsculo Criaturas en la luz (1973), con poemas extraídos de su libro previo Redención del día. Algún tiempo después, redactó un estudio sobre la poesía costarricense para La estafeta literaria $^{6}$, el primer trabajo que apareció en España sobre la lírica costarricense contemporánea, y reafirmó ese interés por la poesía española con un estudio más extenso sobre Miguel Hernández, que presentó en la Universidad de Costa Rica.

Una nueva oleada de poetas costarricenses a tierras españolas ocurrió a lo largo del decenio de 1980. Para sorpresa de muchos, en 1979 Laureano Albán obtuvo en Madrid, donde acababa de instalarse, el prestigioso premio Adonais, por su Herencia del otoño. Al margen de la indudable calidad de los poemas premiados, para algunos de

6 Carlos Rafael Duverrán, "La nueva poesía costarricense (notas al pie de una antología)", La estafeta literaria. 519 (1973) 26-28. 
nosotros aquel suceso fue un reconocimiento, por parte de poetas y críticos españoles, a los aportes de una generación relativamente joven de poetas costarricenses; habían premiado a "uno de los nuestros". Años más tarde, Julieta Dobles también vio publicado en Madrid su libro Hora de lejanías, recibido con un accésit al mismo Adonais. Albán siguióalcanzando reconocimiento allende el territorio costarricense y nuevos libros suyos aparecieron sucesivamente en Madrid, en León, en Huelva y en Zaragoza. Las cartas estaban echadas para las nuevas generaciones costarricenses.

En 1985 otro grupo de poetas asistió a un encuentro de escritores hispanoamericanos, llevado a cabo en Madrid, que dejó marca en algunos. Asistimos - ya tengo que hablar en primera personaCarlos Cortés, Ana Istarú, Rodrigo Soto, Oscar Álvarez, Armando Antonio Ssacal, Vernor Muñoz y yo. Ana consiguió al poco tiempo abrirse espacios en el difícil mundo editorial madrileño; Carlos Cortés volvió a España dos o tres años después a cumplir una pasantía en periodismo, en Navarra. En 1987, gracias a la acuciosidad del propio Cortés, apareció en la prestigiosa revista madrileña Poesía, una selección anotada de poesía costarricense contemporánea; figuraban poemas de Osvaldo Sauma, de Diana Ávila, de Mía Gallegos, de Gerardo Morales y míos ${ }^{7}$.

Durante poco más de dos años, yo me radiqué en Madrid desde el otoño de 1987, gracias a una beca para hacer un posgrado en la Universidad de Madrid. Tenía proyectado estudiar la poesía del mexicano Xavier Villaurrutia, a quien había leído con entusiasmo y constancia. Sin embargo, mi tutor me persuadió a dedicarme a lo que él creía más oportuno; parece que había caído en sus manos un ensayo mío sobre la poesía costarricense y juzgó que la tesis de grado debía desarrollar y completar aquellas primeras ideas. Y así fue: durante los siguientes dos años asistí a los cursos de rigor, que me dieron la oportunidad de conocer de primera mano el desarrollo y la situación

7 Carlos Cortés, selección y notas. "Una panorámica de la poesía costarricense actual", Poesía (Madrid). 29 (1987) 143-156. 
de la poesía española contemporánea. Uno de mis placeres semanales fue asistir a las charlas (más que lecciones) que el poeta Carlos Bousoño tenía a su cargo; su tema permanente: los secretos de la evolución de la poesía española, desde el impresionismo hasta hoy. Concluido el período de clases magistrales y otras tareas de investigación literaria, retomé mis notas, las actualicé y me di a la tarea de redactar un extenso y minucioso estudio sobre la poesía costarricense; así lo mandaban las normas universitarias. Lo titulé Códigos estéticos en la poesía de Costa Rica, que presenté y leí en Madrid en febrero de 1991. Hoy pienso que aquel profesor me encargó el estudio no sólo porque vio la oportunidad de que en el medio español se ampliase el conocimiento de las letras hispanoamericanas, reducidas casi siempre a tres o cuatro países, sino también porque el canon de la crítica suele ser excluyente y a veces arbitrario. ¿Por qué se conoce más a Gonzalo Rojas que a Isaac Felipe Azofeifa?; ¿quién era aquel costarricense ganador de un Adonais?; ¿a cuál literatura pertenece la obra de Eunice Odio: a la mexicana o a la costarricense?

La poesía costarricense se ha leído un poco más en España desde hace dos o tres lustros. El breve artículo de Duverrán, de 1973, fue pionero en el mejor sentido de la palabra: precursor y creador de espacios por explorar; después apareció otro artículo suyo en Cuadernos Hispanoamericanos, revista entonces dirigida por el poeta Félix Grande $^{8}$. Las mejores comunicaciones con la España democrática contemporánea y una nueva manera de acercarse a las letras hispanoamericanas de hoy, por parte de los críticos de procedencia académica, han reafirmado ese interés. Dos o tres artículos más sobre la poesía costarricense, escritos por algunos de nosotros, han aparecido en buenas revistas madrileñas, durante la última década del siglo $\mathrm{xx}^{9}$.

8 Carlos Rafael Duverrán, "Poesía costarricense contemporánea". Cuadernos Hispanoamericanos. 301 (1975) 33-76.

9 Con ocasión de la muerte de Isaac Felipe Azofeifa. el director de Anales de Literatura Hispanoamericana, de Madrid. me pidió una breve semblanza del poeta costarricense. que apareció en 1998 (ALH. 1998. 27: 19). Pasado un lustro. Cuadernos Hispanoamericanos volvió a fijar su 
Mís recientemente, otros poetas jóvenes hay recibido reconocimien(1)s y premios; entre ellos José María Zonta y Luis Chaves ${ }^{10}$.

Por nuestra parte, ¿cómo hemos visto la poesía española? A lo largo del siglo xx la hemos leído de diversas maneras, porque también la actitud de los poetas costarricenses hacia la tradición de la poesía española se ha modificado. En una primera etapa se leía lo que se tenía a mano; es decir, la lírica decimonónica (Bécquer, Núñez de Arce, Campoamor). Luego las lecturas se fueron renovando con las corrientes modernas: las prosas y versos de Valle-Inclán, de los Machado, de Juan Ramón Jiménez ${ }^{11}$, y casi al mismo tiempo las simpatías y las lecturas se detuvieron en el entorno literario inmediato abierto por la poesía hispanoamericana. Las aficiones literarias cambiaron y siguen cambiando; los mapas poéticos se desdibujan y se redibujan con otros territorios y nuevas zonas culturales y, con ello, lingüísticas. De una pequeña encuesta que realicé entre varios amigos para redactar estas páginas, extraigo lo siguiente: que de la poesía española de hoy se conoce en parte la obra de José Hierro, Pere Gimferrer, Leopoldo de Luis, Jaime Gil de Biedma, Luis Rosales, Gloria Fuertes, Félix Grande o Ángel Crespo; y sólo indirectamente se tiene noticia de Dámaso Alonso, Francisco Brines, Antonio Colinas o Carlos Barral. Hay dos notables ausencias: Claudio Rodríguez y Carlos Bousoño. Quedan esperanzas: algunas antologías de poesía española contemporánea han llegado a nuestras librerías de literatura y se han vendido en pocos días.

mirada en las letras costarricenses, cuando Carlos Cortés envió su artículo "Fragmentos y márgenes de la literatura costanicense" $(\mathrm{CH}, 301,1995$ : 33-76). y posteriormente "La poesía costarricense de fin de siglo" ( $\mathrm{CH}, 588,1999: 37-44)$; también en el n² 28, de 1999 de Anales de literatura Hispanoamericana se publicó mi estudio "Paisajes y laberintos de la memoria", sobre la poesía centroamericana contemporánea.

10 De Luis Chaves, la prestigiosa editorial Visor le acaba de publicar su libro Chan Marshall, libro de poemas premiado en Cuenca. Entre 1985 y 2005 se han publicado en España obras de Ana Istanú, Carlos Francisco Monge, Laureano Albán, Carlos Cortés, Anabelle Aguilar, Carmen Naranjo, Eunice Odio, Floria Herrero y Luis Chaves.

11 Nadie ha estudiado aún las relaciones entre la prosa impresionista de Juan Ramón Jiménez y las de las costanicenses Blanca Milanés o Clara Diana. 
En estos albores del siglo xxI, sin embargo, estamos presenciando el desarrollo de unos recursos nuevos de comunicación, sustancialmente diferentes del libro, del periódico, de la radiodifusión o de la telefonía. Desde luego, me refiero a la red internacional de información digital, disponible hoy día en cualquier caf etería, en la oficina del profesor, en nuestro dormitorio, en la tienda de abarrotes y hasta en la zapatería de la esquina. La palabra ya se ha hecho familiar: la internet. Parece el nombre de alguna compañía asegurạdora, de una agencia de noticias o de un detector de metales preciosos; pero no es así. Es una formidable biblioteca virtual, en permanente formación y enriquecimiento, actual, actualizada y actualizable; tal vez como la soñaron las mejores mentes de literatura fantástica. Pero no hay ilusiones ni deseos ni fantasmagorías; es lógica pura, circuitos integrados e información acumulada. Con el artilugio de una computadora entramos en comunicación con las grandes bibliotecas del planeta, con las editoriales que apenas unas horas antes han avisado de sus novedades del día, con revistas, librerías, antologías, con escritores, academias, críticos literarios, historiadores; información última sobre congresos, simposios, encuentros ${ }^{12}$.

Esto ha modificado y modificará aun más las relaciones entre la poesía española contemporánea y la costarricense, empezando por la posibilidad de leer mucho más que lo leído hasta ahora. Hoy día contamos con muchos poemas en centenares de espacios de la red; de voces conocidas y de otras que hallamos por primera vez. Hay sitios

12 Hace unas pocas semanas (diciembre de 2005) pudimos leer el incendiario discurso de aceptación del Premio Nobel de Literatura que el escritor inglés Harold Pinter había de of recer pocas horas después ante los ilustres de la Academia sueca. Una anécdota de estos días globalizados por la Internet: la noche del viemes 20 de abril de 2002 me encontraba explorando noticias en las páginas digitales del diario El País de Madrid. En uno de sus principales titulares del día se anunció que el poeta José Hierro acababa de fallecer. según un parte médico. La fecha del periódico indicaba sábado 21 de abril de 2002; es decir, que en rigor me enteré del acontecimiento el día anterior. Bajé al comedor y de jé ir la noticia, que a todos les pareció solo producto de mis alucinaciones o del insomnio: “¡Mañana murió José Hierro!”, les dije. 
(hablo en los términos informáticos actuales) con mucha información sobre poetas contemporáneos, y generosas selecciones de su obra; incluso podemos hasta oír su voz grabada leyendo sus poemas. Esta oferta era poco menos que inalcanzable hace apenas veinte años, para un modesto estudiante universitario enamorado de la poesía.

Cuando pienso en las literaturas de diversa procedencia, insisto en el principio de que el verdadero territorio de la literatura no es tanto una región o una época, como la lengua en la que se ha engendrado. Como los naturales, el territorio literario no tiene por qué ser uniforme y plano; su topografía es compleja y variada: hay montes, llanuras, abismos, oteros, riachuelos, grandes correntadas, riscos, senderillos, montañas escarpadas, horizontes sin límites... El español como idioma goza de una tradición literaria riquísima, que empezó y se desarrolló en tierras peninsulares y se ramificó en mil direcciones en nuestro continente. Las letras costarricenses han recibido influencias, ciertas formas de sujeción y hasta podríamos encontrar abiertas imitaciones; pero sobre todo hallamos semejanzas, simpatías, coincidencias y exploraciones análogas. Por ejemplo, hay relaciones significativas entre la sobriedad poética y profundamente simbólica de la poesía de Antonio Machado y la interiorización sentimental del paisaje costarricense en la poesía de Rafael Estrada o de Blanca Milanés; también podríamos detenernos en aspectos como el solipsismo estético y sentimental de los poemas del español Luis Cernuda, del mexicano Xavier Villaurrutia y del costarricense Carlos Rafael Duverrán; ¿hay algún estudio que haya cotejado con argumentos creativos y novedosos las obras poéticas de Blas deOtero y de Jorge Debravo; la de Gloria Fuertes con la de Virginia Grütter?

Lo que podría definir las letras nacionales es su manera de imaginar la patria, su historia, sus circunstancias. Cuando un poeta costarricense escribe, lo hace desde Costa Rica; por la tinta que traza cada uno de sus versos corren también una historia, unos paisajes, un talante social, unas expectativas, una ética. Lo mismo da que el poema lleve por título «Vuelo supremo», «Se oye venir la lluvia», «Apología 
de todo desde un cielo estrellado» 0 «Provinciano hasta la muerte» ${ }^{13}$. Pero los poemas no están hechos de ideas (ni de ideologías) sino de palabras; nuestro poeta inventa un discurso cuyo lenguaje ha pasado por las lecturas de algún maestro mexicano suyo y el de éste por las de un colombiano o un uruguayo, y ellos seguramente leyeron y adoptaron a los grandes clásicos españoles. De esos profundos manantiales brotan las verdaderas relaciones entre la poesía costarricense y la española; por eso la crítica no debería ocuparse tanto de las relaciones entre la poesía española y la costarricense, como de analizar por qué no se han estudiado con más detenimiento e intensidad.

Esas relaciones literarias empezaron como la continuación de una rica trayectoria acumulada durante siglos. Hoy la situación es otra: los poetas españoles forman multitud; hay una consolidada práctica de crítica literaria en los mejores recintos académicos y una industria editorial envidiable. Si nos comparamos con lo que ocurría hace cuatro décadas, en nuestro medio ya no son pocos los libros de poesía que se publican al año; la crítica literaria, sobre todo de procedencia universitaria, ha cobrado reputación y en algunos casos brillo, con estudios sobre autores, períodos o géneros de las letras nacionales. A esto hay que añadir que algunos libreros de San Joséhan procurado poner a nuestro alcance las novedades literarias de alguna poesía española de hoy.

Son relaciones con un pasado, con un presente y es de presumir que con un futuro. Hace cien años, los poetas costarricenses mostraron una filial lealtad a la tradición literaria hispánica, lealtad que hoy día nos podría resultar incómoda, aunque jamás reprochable; la lírica costarricense estaba en sus albores. En nuestros días, las relaciones son más complejas y múltiples, aunque encierran una paradoja: proporcionalmente conocemos menos de la lírica española que nuestros escritores de hace ochenta o cien años. Ya he dicho que las posibilidades actuales de «leernos» más (aunque solo sea entre los poetas) han

13 Estos son tan solo ejemplos. "Vuelo supremo" e s de Julián Marchena: «Se oye venir la lluvia». de Isaac Felipe Azofeifa: "Apología de todo desde un cielo estrellado”. de Rodrigo Quirós y "Provinciano hasta la muerte" de Alfonso Chase. 
crecido con la internet; podemos conocernos y reconocernos de nuevo en los poemas de una lengua común. Las relaciones se han hecho dinámicas y dialogantes; es decir, verdaderamente recíprocas. En estos días que corren nos enteramos de las novedades editoriales aparecidas ayer mismo; conocemos la reacción de los lectores y leemos las reseñas en los periódicos digitales. Estamos al corriente, como lo están también nuestros potenciales lectores peninsulares. Aparte de las casas editoriales, las mejores fuentes de conocimiento y de comunicación de las literaturas son los buenos suplementos literarios, las revistas y los departamentos universitarios de lengua y literatura.

Y aunque el futuro no existe sino como proyección existencial, ¿qué podemos esperar de las relaciones entre nuestra poesía y la española en los años venideros? Acaso la situación imaginable sea la siguiente: nuestra pequeña nación estará cada vezmás insertada en una compleja red de condiciones políticas, geográficas, económicas y tecnológicas de alcance planetario; es decir, globalizadas. Tal vez dejaremos en el olvido, por necesidad o por incuria, muchos de los considerados valores esenciales de nuestra identidad o nacionalidad. Quedarán entre los escombros de las bibliotecas aquellos versos de Aquileo, las guarias de Lisímaco Chavarría, los errantes pájaros marinos, el sauce del patio familiar, los viernes santos, los días y territorios del trópico verde. Los grandes cataclismos o las grandes proezas serán de todos o para todos; y los poetas, siempre vigilantes, así lo entenderán y desde esa conciencia crearán sus poemas. Ya no habrá entonces poesías nacionales sino poemas desde aquí o desde allá, convergiendo, dialogando, significando de veras. Ese futuro, que siempre está a la vuelta de la esquina, no es un accidente de las circunstancias, sino un fértil terreno donde podemos sembrar ideas, propuestas y acciones. Más revistas literarias; casas editoriales comprometidas con las mejores plumas; universidades e institutos que estudien y protejan el patrimonio literario; mentes, en fin, que no claudiquen sujetas al pasado, sino que alienten el valor de lo actual. 
Porque los poemas, aunque hablen del pasado o sueñen con el futuro, siempre se escriben desde el presente.

$$
* * *
$$

Queda mucho por decir y mucho por hacer. Señalé al principio que debemos conocer los orígenes de la poesía costarricense, sus fuentes nutricias, sus afinidades, sus entornos. Ha pasado mucha agua bajo los puentes literarios desde que alguien recitó las coplas de Domingo Jiménez; y ahora recogemos la antorcha que nos dejan los poetas, pensadores y estudiosos de nuestras letras.

Como algunos de ustedes deben de saberlo, yo he vivido la literatura surcando dos ríos paralelos: la creación y la docencia. Hay quienes todavía piensan que son oficios excluyentes; y muchos han querido ver en el poeta y en el profesor de literatura dos modos opuestos de llegar a la poesía. Nada más lejos de la verdad, amigos. Es cierto que la poesía no nace en las universidades, pero también lo es que la mayor y mejor atención a la poesía moderna se ha puesto en las aulas académicas, en los cursos de literatura, en congresos, simposios, encuentros, seminarios y mil variedades más. Nosotros no conocimos las grandes catedrales de la poesía en las calles y buhardillas de París, Dublín, Buenos Aires o Lisboa, sino en las bibliotecas de amigos y maestros, en las de las universidades, en los anaqueles de las librerías. La poesía — qué duda cabe - germina en los bares, en las calles abandonadas, en los suburbios, en la soledad de un puente, tal vez en los prostíbulos, en los parques, en los atardeceres costeros, al pie de los volcanes, en el abrazo al amigo, en hospitales, en una ermita, en la celda. Pero también se origina en el silencio de una habitación, detrás del escritorio de un buen estudiante, en la banca de un museo, viajando en tren, entre los rumores desconocidos de la madrugada, junto a la mesa del laboratorio, esperando el autobús, bajando del avión, en la sala de espera, cenando, charlando, comprando el periódico. Nace de la historia pero se realiza en y con el lenguaje de quien sabe vivirla. 
A despecho de los platónicos, la poesía no es universal, ni cósmica, ni eterna. Está hecha de acontecimientos, aunque busca extraer de ellos algo parecido a la inmortalidad; seguramente porque nuestra cultura nos ha llevado a aspirar a la trascendencia. Puede que esa quimera me haya impulsado a firmar hace ya treinta años, con tres amigos más, un manifiesto que vibraba con esas ideas; pero estoy persuadido de que la poesía, lejos de buscar la infinitud, es testimonio de las costumbres, de la fugacidad, de lo presente. Es una tentativa de sacarles provecho a los instantes y sentido a los episodios cotidianos. Acaso lo que tiene de universal y de perdurable sea el proyecto de fingirnos o soñarnos más allá de las circunstancias, como partículas luminosas en el cosmos; pero no hay poesía si esos espejismos, esas fantasmagorías o esas certidumbres no se convierten en imágenes, en palabras; nada más.

Un poeta español del siglo XVII escribió inolvidables sonetos sobre la fugacidad de la vida y la incertidumbre del destino humano. Tal vez lo hizo desde un oscuro desván y a la luz de un candil. Un poeta costarricense, siglos más tarde, lee con emoción aquellos versos; los repasa, vuelve sobre ellos una y otra vez: está dialogando con el poeta castellano. Ni el tiempo ni la patria los reunieron; han sido las palabras. 